\title{
Autoconsciência, Imagens Mentais e Mediação Cognitiva
}

\author{
Self-Awareness, Mental Imagery and Cognitive Mediation
}

\author{
Alexsandro Medeiros do Nascimento* \& Antonio Roazzi \\ Universidade Federal de Pernambuco, Recife, Pernambuco, Brasil
}

\begin{abstract}
Resumo
O estudo encaminhou o teste empírico da hipótese de mediação cognitiva de autoconsciência através de imagens mentais e das relações da mediação icônica com habilidades de visualização, bem como de exame das qualidades psicométricas da Escala de Autoconsciência Situacional e o Teste de Habilidades de Visualização de Imagens Mentais, com suas duas séries independentes - Self e Não-Self, visando seus usos em pesquisas futuras. O estudo ex-post-facto completo foi conduzido com 958 universitários, os quais responderam os instrumentos de forma individual ou coletiva, sendo os dados analisados através de procedimentos de Análise Fatorial, coeficiente de correlação de Pearson, técnica de Regressão Linear e Análises Multidimensionais tipo SSA. As análises efetuadas corroboraram a hipótese de mediação cognitiva de autoconsciência por imagens mentais, e de que a mediação icônica tem uma relação consistente com o nível de desenvolvimento das habilidades imaginativas. Palavras-chave: Autoconsciência situacional, imagens mentais, mediação cognitiva, habilidades de visualização, avaliação psicométrica.
\end{abstract}

\begin{abstract}
The present study was carried out to empirically test the hypothesis of cognitive mediation of self-awareness through mental imagery and the relations of iconic mediation with visualization skills. It also examined the psychometric qualities of the Situational Self-Awareness Scale and the Visualization Test (Mental Imagery Skills) with its two independent series - Self and Non-Self, enabling their use in future research. The complete ex post facto study was conducted with 958 university students, who answered the instruments individually or collectively. The data were analyzed using factor analysis procedure, Pearson correlation coefficient, linear regression technique and multi dimensional analysis. The analyses corroborate the hypothesis of cognitive mediation of self-awareness through mental imagery and that iconic mediation has a consistent relationship with the level of development of imagery skills.

Keywords: Situational self-awareness, mental imagery, cognitive mediation, visualization skills, psychometric evaluation.
\end{abstract}

É unanimidade entre os teóricos do Selfe da Autoconsciência delimitar o inicio do estudo moderno desses tópicos aos primeiros anos da década de 70 do século XX com a publicação das pesquisas de Duval e Wicklund (1972) que suportaram a formulação da Teoria da Autoconsciência Objetiva (OSA Theory, ver Buss, 2001; Fenigstein, Scheier, \& Buss, 1975; Morin, 1992, 1995, 1998, 2004; Morin, Everett, Turcotte, \& Tardif, 1993).

Durante quase todo o século XX não houve considerável exame desta questão, devendo a psicologia aos seus sub-campos clínico-psicoterápico e aplicados, o pouco que se sabia sobre este sistema cognitivo, conforme historia Buss (2001). Deve-se aos trabalhos experimentais de Duval e Wicklund (1972) o lançamento da pedra fundamental do campo de investigação científica da autoconsciência em

\footnotetext{
* Endereço para correspondência: Universidade Federal de Pernambuco, Centro de Filosofia e Ciências Humanas, Rua Acadêmico Hélio Ramos, s/n, Cidade Universitária, Recife, PE, Brasil 50670-901. E-mail: alexmeden@ hotmail.com
}

tempos modernos, recuperando a pergunta pela qualidade autoreflexiva da consciência de seu ostracismo pela leva behaviorista e de seu caráter não tematizado sistematicamente oriundo das correntes psicodinâmicas e humanistas da psicoterapia psicológica (ver Silvia \& Duval, 2001).

Ao conceituarem autoconsciência como processo auto-avaliativo, Duval e Wicklund (1972) descrevem sua dinâmica organizativa quando o self de forma automática compara autoconteúdos atuais no fluxo da consciência com padrões internalizados de correção (o que é certo/ errado, ético/anti-ético, belo/feio, valoroso/sem valor, etc.), devendo-se a extensão do intervalo entre as duas instâncias (o self real e o self ideal) determinar o tipo de experiência emocional resultante, se afeto prazeroso ou ansiedade, cujo conteúdo e intensidade determinarão a direcionalidade futura dos focos atencionais - se o individuo se manterá em estados autoconscientes ou se tentará tenazmente desviar o foco do self para objetos não-self (Duval \&Wicklund, 1972). Em continuidade a este programa de pesquisa, logo em seguida Fenigstein et al. (1975) com base em estudo 
de corte fatorial traçaram a distinção ainda em voga e com importantes conseqüências na pesquisa empírica entre autoconsciência em sua dimensão estado (self-awareness) e em sua dimensão traço (self-consciouness), onde a primeira refere-se aos estados transitórios de atenção autofocalizada sob controle de estimulação ambiental, de que resulta a experiência pontual de se estar consciente de si, e na última um traço estável da personalidade, relativamente independente de estímulos autofocalizadores, embora resultante da história individual de operacionalização do autofoco, seu sedimento desenvolvimental. Ao primeiro caso dá-se o nome de autoconsciência situacional - foco deste estudo, e ao segundo autoconsciência disposicional (Govern \& Marsch, 2001).

As formulações iniciais da teoria OSA têm se mantido ainda em validade e com robusto corpo de confirmação experimental (ver Duval, Silvia, \& Lalwani, 2001; Govern \& Marsch, 2001; Morin, 1995; Silvia \& Duval, 2001; Silvia \& O'Brien, 2004), embora permaneçam certos pontos de desconhecimento no paradigma em foco, como a questão da natureza da autoconsciência e sua estrutura (se uni ou multidimensional), a da mediação cognitiva desse processo, e as suas relações com os demais sistemas cognitivos (Nascimento, 2008), principalmente em relação à consciência, uma vez que se considere a autoconsciência como sendo uma "consciência de alta ordem" (ver Morin, 2002). O enlaçamento orgânico deste sistema cognitivo com os demais sistemas da cognição levanta a questão ainda atual formulada por Gibbons (1990) sobre o que acontece cognitivamente quando alguém está autoconsciente, pergunta reformulada em Morin $(1998,2004)$ como sendo da ordem da mediação cognitiva, ou de quais processos cognitivos suportam estados autoconscientes, pergunta a qual tem levado o referido autor a sucessivos exames meta-teóricos desde a formulação inicial a partir de sua tese de doutorado (ver Morin, 1992), até os trabalhos mais recentes (ver Morin, 1995, 1998, 2002) e a aparição pública de seu modelo teórico de autoconsciência que tem na mediação cognitiva, e na mediação cognitiva por autofala em especial, seu eixo central de construção (Morin, 2004).

Para o referido autor, autoconsciência é instanciada a partir de processos cognitivos autorepresentacionais, os quais se utilizam de distintos sistemas de representações para gerar pensamentos de alta ordem, gerando uma redundância de informação dentro do self e re-apresentação (tradução) de auto-aspectos específicos, os quais podem assim ser observados, avaliados comparativamente com padrões internalizados, gerando respostas específicas que aumentarão ou não a probabilidade de manutenção do autofoco levando-se em conta a distância percebida entre estados atuais do sistema do self e suas representações ideais, permitindo a expansão de mecanismos de disparo da autoconsciência oriundos do processo social. Assim, autofala reproduz mecanismos sociais geradores de autoconsciência replicando internamente ao self a tomada de perspectiva e avaliações refletidas, os quais ao possibilitarem a re-apresentação continuada de experiências self-relacionadas propiciam autoconsciência fora de interação social na ausência distendida temporal e espacial de outros selves, funcionando como um mecanismo básico de construção do autoconceito (Morin, 1995).

A hipótese da mediação cognitiva por autofala de Morin descrita suscintamente acima tem estado na base de vários testes empíricos da teoria desde suas formulações iniciais, como no estudo experimental com base no paradigma metodológico da fala privada onde 32 crianças com idade média de 6,6 anos foram submetidas à condição com espelho (experimental) e sem espelho (controle) a fim de se atestar a relação entre estados autoconscientes e a fala privada como índice externo da fala interna (Morin \& Everett, 1991); também no estudo com 85 estudantes universitários canadenses para verificação da relação entre quantidade de autofala e níveis de complexidade do autoconceito (Morin, 1995), e no estudo com uma amostra canadense de 438 indivíduos onde se investigou a relação entre quantidade de exposição prévia a estímulos autofocalizadores e os níveis de autoconsciência privada e pública (Morin, 1997), entre outros que tem alicerçado a hipótese da mediação cognitiva de autoconsciência por autofala.

Em Morin (1998) a hipótese da mediação cognitiva é alargada e formalizada de modo a contemplar outro processo autorepresentacional com base nas imagens mentais, onde a análise de suas propriedades codificadoras as revela enquanto tendo um poder efetivo de instanciar estados autoconscientes, tanto quanto a autofala o faz. Imagens mentais reproduzem mecanismos sociais geradores de autoconsciência, como a tomada de perspectiva onde o individuo se vê como provavelmente é visto pelos outros, as audiencias onde inferências sobre o self podem ser extraídas pela visualização no plano mental das respostas dos outros ao funcionamento geral do indivíduo, além do que as mesmas permitem ao self de visualização de aspectos da corporeidade fora dos processos perceptivos imediatos. Apesar do trabalho de burilamento teórico-conceitual posterior que culminou na formalização de seu modelo de autoconsciência, Morin (2004) assegura não ter havido ainda o teste empírico desta parte do modelo consoante às mediações icônicas, mesmo havendo robusta evidência indireta de sua efetividade, como nas experiências autoscópicas as quais, conforme pontua Kitamura (1985), em distinguindo radicalmente experiências visuais de tipo perceptivo e as geradas por imagens mentais, descreve estados autoconscientes pela experienciação do self físico em modo puramente cognitivo, em meio espacial interno.

Além das indicadas por Morin, na pesquisa sobre Fenômenos Autoscópicos mais evidências podem ser encontradas. Mohr e Blanke (2005) sistematizam as evidências empíricas para fenômenos autoscópicos em três tipos principais de ocorrências, (a) as chamadas Experiências-Fora-do-Corpo quando pessoas experienciam seu self ou centro de consciência fora do corpo físico e situado num plano elevado, podendo haver em alguns casos visualiza- 
Nascimento, A. M. \& Roazzi, A. (2013). Autoconsciência, Imagens Mentais e Mediação Cognitiva.

ção do corpo físico num plano mais abaixo, (b) alucinações autoscópicas quando indivíduos visualizam um segundo corpo próprio num plano extra-corporal, porém, com o centro da consciência permanecendo no corpo original, e (c) heautoscopy, uma forma híbrida em que o individuo visualiza seu duplo num plano extra-corporal, mas sem poder decidir se seu self está no corpo físico ou no corpo do duplo, ou ainda quando tem experiências alternadas das perspectivas visuais, ora no corpo original ora no corpo do duplo. Nas três situações, o individuo visualiza um segundo corpo próprio com variados graus de separação self-corpo, numa dinâmica psicológica totalmente construída na interseção de estados autoconscientes e imageria cognitiva (imagens mentais).

Se os recortes teóricos apresentados oferecem uma perspectiva local para a mediação cognitiva por imagens mentais (estudos de autoconsciência e de fenômenos autoscópicos), levar a questão a uma teoria de cognição geral fornece bases bastante sólidas para fundamentação da hipótese. A Teoria do Código Dual de Allan Paivio $(1986,2006,2007)$ fornece um instrumental conceitual que suporta a hipótese da mediação cognitiva de autoconsciência por imagens mentais, ao propor para todo e qualquer possível objeto de captura cognitiva uma inscrição nos dois sub-sistemas de base da cognição, o verbal e o imagético, com conexões fechadas ligando a dupla inscrição. Sendo o self um objeto para si tanto quanto para os outros (Blumer, 1969/1998; Mead, 1934/1972), sua construção necessariamente é de tipo trans-modal, onde concorrem abundantes materiais não-verbais dos primórdios do desenvolvimento cognitivo anteriores à aquisição da linguagem, ao lado de material semiótico de tipo verbal disponibilizado no fluxo da interação social; o autoconceito resultante será conformado numa rede de self-schemata visuais e verbais, em níveis de crescente complexidade cognitiva ao longo do desenvolvimento ontogenético (ver Paivio, 2006).

Aqui cabem hipóteses específicas sobre um possível papel mediador das imagens mentais na instanciação de autoconsciência, a qual deverá ter uma história de desenvolvimento cheia de vicissitudes, a depender dos tipos de contexto em que a mesma gradualmente emerge, se ambientes ricos ou pobres de estímulos autofocalizadores (Morin, 1995, 1998), com conseqüências drásticas em contextos ambientais onde imagens do self não estão disponíveis em fartura como desertos, por exemplo, ou prescrições culturais que vetam a contemplação do self físico em superfícies espelhadas (Morin, 1998), hipóteses consoantes com a expectativa teórica de Paivio (2006, 2007) para uma história contextualmente situada de desenvolvimento do duplo sistema de codificação a partir da percepção visual inicial de objetos, pessoas, eventos e relações. Seguindo-se de perto os insights deste autor, o desenvolvimento das inúmeras operações de visualização descritas na literatura experimental de imagens mentais deve ter uma conexão fechada com os ambientes físicos em especial, mas também os de toda a visualidade social na história desenvolvimental dos indivíduos, onde sua emergência e fortalecimento ao longo da ontogenia revelará linhas desenvolvimentais graficamente singulares, com marcantes diferenças individuais na operacionalização de tais habilidades de visualização, hipótese que já possui marcantes evidências comprobatórias recentes (ver Prieto, 2008; para apoio na literatura menos recente ver Shepard \& Cooper, 1986).

A pesquisa das operações de processamento e manipulação de imagens mentais visuais revelou a existência de várias rotinas cognitivas especializadas como Gerar, Inspecionar, Encontrar, Zoom, Rotar, Transformar, Controle Cinético, Panoramizar e Vivacidade/Vividez, sendo a nomeação destas de caráter auto-explicativo, onde "gerar" implica em criar voluntariamente imagens e cenas fixas ou cinéticas (com movimento), "inspecionar" ou esquadrinhar indica a capacidade cognitiva de observar as relações espaciais internas a uma imagem ou cena, "encontrar" o poder de localizar um aspecto específico de uma imagem ou cena ou localizar um objeto específico em meio a um conjunto de imagens mentais no meio espacial interno, "zoom" a capacidade de aproximação com fins de visualização da imagem ou cena, "rotar" a capacidade de girar mentalmente objetos no meio espacial interno, "transformar" o modificar voluntariamente imagens e cenas, alterando-as e combinando-as de formas diversas e "panoramizar" a operação de manipulação que permite traçar um panorama de uma imagem mental, afastando a mesma para visualizá-la de forma ampla, sendo a "vividez" referente à qualidade da visualização dessa visualidade cognitiva no plano espacial interno (ver Eysenck \& Keane, 1994; Finke, 1989; Paivio, 1986, 2007; Prieto, 2008; Pylyshyn, 2002; Shepard \& Cooper, 1986).

A possibilidade de se ter acesso eficiente a estas operações de visualização deve ter consequências no desenvolvimento da autoconsciência situacional e disposicional, pois ter habilidades robustas de visualização cognitiva coloca-se como uma possibilidade a mais além da autofala para se instanciar reflexividade dentro do self e assim se permitir a análise de auto-aspectos em todos os domínios da estrutura do self e do autoconceito (Morin, 2004). Da mesma maneira, indivíduos com precárias habilidades de visualização de imagens mentais devem ter níveis menos pronunciados de autoconsciência situacional e autoconceitos menos elaborados (Morin, 1995, 1998, 2004).

A partir da base teórica descrita o estudo investigou a hipótese de mediação cognitiva de autoconsciência através das imagens mentais e as relações da mediação icônica com as habilidades de visualização dos indivíduos investigados bem como a estrutura relacional dos fatores de autoconsciência situacional, com a expectativa teoricamente baseada de ser tal mediação possível, de ela ter uma relação com o nível de desenvolvimento das habilidades imaginativas e de haver um elo funcional e desenvolvimental entre a interface de valências positiva e negativa (reflexão-ruminação) do autofoco com as imagens mentais. Também consistiu de 
um exame das qualidades psicométricas dos instrumentos construídos para teste das hipóteses da pesquisa, a saber, o Teste de Habilidades de Visualização de Imagens Mentais (THV), com suas duas séries independentes - a Série Self (THV-S) e a Série Não-Self (THV-NS), visando seu uso em pesquisas futuras.

$\mathrm{O}$ estudo construiu-se a partir de um delineamento de tipo ex-post-facto, sem manipulação direta das variáveis, tendo como objetivo a descrição das intercorrelações entre as mesmas, sua força associativa e direcionalidade (Kerlinger, 1979/2003). De forma geral, procurou verificar as seguintes hipóteses (H) principais (1 e 2) e secundárias (3, 4 e 5): H1. Autoconsciência Situacional em seus modos Reflexão e Ruminação correlaciona-se positivamente com Mediação Icônica (teste da hipótese de mediação); H2. O Teste de Habilidades de Visualização de Imagens Mentais (THV) possui boas qualidades psicométricas em ambas as séries de que é constituído (Self e Não-Seḷ̂); H3. Os processos de visualização/manipulação de Imagens Mentais são positiva e fortemente correlacionados entre si; H4. Autoconsciência Situacional correlaciona-se positivamente com Habilidades de Visualização de Imagens Mentais, em especial, seu fator de Mediação Icônica (teste da hipótese de desenvolvimento conjunto da autoconsciência e das imagens mentais); e, H5. Autoconsciência Situacional correlaciona-se positivamente e mais fortemente com a Série Self que com a Série Não-Self do Teste de Habilidades de Visualização de Imagens Mentais.

\section{Método}

\section{Participantes}

Participaram deste estudo 958 estudantes universitários oriundos de instituições de ensino superior públicas e privadas, os quais responderam a ambas as formas do protocolo de pesquisa (Resumida e Completa) para o teste de hipóteses consoante às relações entre a Autoconsciência Situacional e Mediação Icônica. Para o tratamento das hipóteses relacionadas às habilidades de visualização de imagens mentais, participaram 258 estudantes extraídos da amostra completa supracitada, os quais responderam a Forma Completa do protocolo de pesquisa que continha o Teste de Habilidades de Visualização (THV), sendo destes 132 de sexo masculino $(51,16 \%)$ e 126 de sexo feminino $(48,84 \%)$.

\section{Instrumentos}

Os participantes responderam a um questionário auto-administrado distribuído pelo pesquisador na forma de uma apostila em duas formas (Resumida e Completa) contendo as medidas usadas neste estudo - a Escala de Autoconsciência Situacional e o Teste de Habilidades de Visualização de Imagens Mentais (THV), as quais serão descritas brevemente a seguir.

Teste de Habilidades de Visualização de Imagens Mentais - THV. Bateria composta por duas séries sepa- radas (Self e Não-Self) e passíveis de utilização individualizada e criada com o objetivo de medir as habilidades de visualização de imagens mentais dos indivíduos a partir de 9 medidas parciais ou tarefas duplicadas nas duas séries referentes a diversas operações de geração, manipulação e processamento de imagens mentais de tipo visual relatadas na literatura especializada como Gerar, Inspecionar, Encontrar, Zoom, Rotar, Transformar, Controle Cinético, Panoramizar e Vivacidade/Vividez (ver Eysenck \& Keane, 1994; Paivio, 1986, 2007; Shepard \& Cooper, 1986), sendo as mesmas operações propostas aos respondentes com manipulação de imagens do self e de um objeto não-self, que neste caso escolhido foi a imagem de um automóvel (ver Escala Completa em Anexos). Os itens receberam respostas numa escala Likert de 05 pontos variando de ' 0 ' a ' 4 ', indicando o primeiro valor ausência de experiência visual e o último visualização com absoluta clareza do que foi solicitado nas instruções dos itens individuais. Os testes de visualização foram divididos em duas baterias (A e B), sendo a última composta dos dois itens de vividez (self e não-self) que continham instruções específicas, o que levou a quando das análises e conseqüente apresentação dos resultados a reconfiguração da numeração dos itens visando-se apresentar as séries (self e não-self) completas, com o último de seus itens sempre enfocando a vividez ${ }^{1}$.

Escala de Autoconsciência Situacional - EAS. Escala de tipo Likert composta por 13 itens e construída para mensuração de diferenças individuais na capacidade cognitiva de autofoco enquanto estado (situacional), com ênfase nas modalidades não-ansiosas da autoconsciência (reflexão) e ansiosas (ruminação) e na mediação cognitiva de autoconsciência por imagens mentais (mediação icônica). Itens típicos da escala são "Neste instante, eu avalio algum aspecto que me diz respeito" (Item 01, Reflexão), e "Neste instante, eu estou me vendo em minha mente" (Item 10, Mediação Icônica), os quais receberam respostas numa escala Likert de 05 pontos variando de ' 1 ' (discordo totalmente) a ' 5 ' (concordo totalmente), no tocante ao julgamento de adequação do conteúdo de cada auto-afirmação do instrumento a como o participante esteve se percebendo no exato instante em que respondeu ao mesmo. A análise da consistência interna pelo Alfa de Cronbach revelou adequados níveis de fidedignidade com alfas de $0,74,0,74$ e 0,69 para os fatores de autofoco - reflexão, ruminação e mediação icônica respectivamente. 
Nascimento, A. M. \& Roazzi, A. (2013). Autoconsciência, Imagens Mentais e Mediação Cognitiva.

\section{Procedimentos}

A coleta teve seu início após a aprovação do projeto pelo Comitê de Ética da Universidade Federal de Pernambuco (UFPE). Após detalhamento dos objetivos da pesquisa e dos requerimentos éticos a ela vinculados, o pesquisador distribuiu os Termos de Consentimento Livre e Esclarecido, os quais foram recolhidos após suas assinaturas pelos respondentes, quando os protocolos de pesquisa nas duas formas (Resumida e Completa) foram entregues aos mesmos, tendo sido necessário para a resposta aos protocolos o tempo médio de 1 hora para a forma completa e de 30 minutos para a forma reduzida.

\section{Resultados}

Como primeiro momento de análise da estrutura da autoconsciência situacional humana verificou-se através do coeficiente de correlação de Pearson as interrelações entre os fatores da escala EAS (ver Tabela 1).

Tabela 1

Correlação entre os Fatores de Autoconsciência da Escala EAS

\begin{tabular}{lcccccc}
\hline \multirow{2}{*}{ Fatores } & \multicolumn{2}{c}{ Reflexão } & \multicolumn{2}{c}{ Ruminação } & \multicolumn{2}{c}{ Mediação Icônica } \\
\cline { 2 - 6 } & $r$ & $p$ & $r$ & $p$ & $r$ & $p$ \\
\hline Reflexão & 1 & & & & & \\
Ruminação & $\mathbf{0 , 3 3}$ & 0,001 & 1 & & & \\
Mediação Icônica & $\mathbf{0 , 3 9}$ & 0,001 & $\mathbf{0 , 2 8}$ & 0,001 & 1 \\
\hline
\end{tabular}

O exame dos $r$ de Pearson das interrelações das variáveis citadas indicou correlações significantes entre todos os fatores da escala EAS, o que corrobora a Hipótese 1 do estudo, com o mais alto escore de correlação acontecendo entre os fatores Mediação Icônica e Reflexão $(r=$ $0,39, p<0,001)$, e o menor escore relacionando os fatores Mediação Icônica e Ruminação $(r=0,28, p<0,001)$. Segundo a grade de Dancey e Reidy (2006) para as magnitudes do $r$ de Pearson, a análise correlacional efetuada com os itens da matriz de correlações evidenciou serem todas as correlações significantes e de fraca intensidade $(r<0,40)$, havendo apenas uma dessas relações cuja intensidade coloca-se no limiar de entrada para o espectro das correlações de intensidade moderada - a já referida anteriormente entre as variáveis (fatores) Mediação Icônica e Reflexão $(r=0,39)$.

Nota-se a consistência considerável das medidas intra-escala, quando os escores $r$ indicaram correlações de intensidade ligeiramente mais acentuada (não tendentes a zero) entre seus itens - todos acima de $0,20(0,28 ; 0,33$; e 0,39 , respectivamente), com uma discreta acentuação da intensidade da associação entre as variáveis (fatores) Mediação Icônica e Reflexão. A correlação significante positiva, mas fraca (abaixo dos escores de correlação considerados de intensidade moderada) encontrada entre Reflexão e Ruminação $(r=0,33, p<0,001)$ replicam no âmbito da autoconsciência situacional achados internacionais de Trapnell e Campbell (1999), e nacionais na pesquisa de Zanon e Teixeira (2006) com a autoconsciência disposicional, achado este que dá força à hipótese de as duas operações de autofoco (reflexão e ruminação) serem dois modos qualitativamente distintos de autoconsciência mas de alguma maneira relacionados. O nível de associação entre as duas variáveis encontrado no presente estudo $(r$ $=0,33)$ - mais forte que a encontrada no estudo com uni- versitários brasileiros de Zanon e Teixeira (2006) de 0,24, indicia a presença de uma organização mais imbricada entre os dois modos de autofocalização, que a pesquisa atual ainda não tem mapeado e explicado suficientemente, dado o $r$ encontrado estar se aproximando do limiar dos escores de Pearson 'moderados' (acima de 0,40), vistos como de intensidade mais considerável na literatura (ver Dancey \& Reidy, 2006).

Ainda em relação ao exame dessa matriz de correlações, faz-se mister a pontuação da discreta preferência associativa da Mediação Icônica pelo fator Reflexão $(r=0,39)$, embora escore não-desprezível tenha sido achado para associação entre o mesmo fator e Ruminação $(r=0,28)$, indicando que o uso das imagens mentais para fins de auto-inspeção pode ser cooptado por ambas as orientações autoconscientes, tanto positivas (reflexão) quanto negativas (ruminação).

O momento seguinte das análises enfocou o exame das qualidades psicométricas do THV em suas duas séries (Self e Não-Self). O exame em separado das duas matrizes de correlações pelo índice Kaiser-Meyer-Olkin revelou KMOs bem acima de $0,70(0,89$, Self; 0,92 , Não-Self $)$, valor que garante segundo Reis (2001) a fatorabilidade da matriz e a existência de componentes latentes a serem extraídos. $\mathrm{O}$ uso do KMO triangulado ao Teste de Esfericidade de Bartlett com as duas matrizes permitiu encaminhar a Análise dos Componentes Principais para extração dos possíveis fatores destas medidas, tendo-se previamente prospectado o número de componentes a serem retidos pelos critérios da Raiz Latente (Critério de Kaiser) e do Gráfico de Declive (Critério de Cattell), os quais conjuntamente salientaram a unidimensionalidade ( 1 único fator) de ambas as medidas, ratificando adequadamente as Hipóteses 2 e 3 do estudo. Vê-se abaixo o resultado do Teste Scree para a Série Self do THV, no qual constata-se um decaimento acentuado dos 
ângulos de inclinação do segundo autovalor em diante, o que sugere a retenção de apenas um componente na análise fatorial. O mesmo se encontrará no exame da matriz da Série Não-Self pelo Teste Scree. Um sumário da avaliação das qualidades psicométricas das duas séries do Teste de Habilidades de Visualização, incluindo-se a Análise dos Componentes Principais e do Alfa de Cronbach pode ser examinado de forma comparativa na Tabela 2.
A estrutura encontrada pela Análise dos Componentes Principais confirmou a unifatoriabilidade de ambas as medidas, e com níveis excelentes de consistência (fidedignidade), com discreta otimização para a segunda série (Não-Self), com alfas recaindo dentro de margens extremamente rigorosas de 0,87 (Série Self) e 0,91 (Série Não-Self) segundo a psicometria (ver Dancey \& Reidy, 2006; Hair, Anderson, Tatham, \& Black, 2005; Reis, 2001). Ressalta-se ainda as altas cargas fatoriais saturando os itens de ambas as medidas.

Tabela 2

Comparativo dos Índices Psicométricos das Séries Self e Não-Self do THV

\begin{tabular}{lcc}
\hline \multirow{2}{*}{ Índices Psicométricos } & \multicolumn{2}{c}{ Teste de Habilidades de Visualização } \\
\cline { 2 - 3 } KMO & Série Self & Série Não-Self \\
Bartlett & 0,89 & 0,92 \\
Kaiser & $776,629, p<0,001$ & $1170,621, p<0,001$ \\
Cattell & 4,38 & 5,31 \\
Cargas Fatoriais & 1 componente & 1 componente \\
Variância Total & $0,82-0,49$ & $0,83-0,50$ \\
Alfa de Cronbach & $48,67 \%$ & $58,95 \%$ \\
\hline
\end{tabular}

Tabela 3

Intercorrelações ( $r$ de Pearson) de Valores do THV (S e NS) e Fatores da EAS

\begin{tabular}{|c|c|c|c|c|c|c|}
\hline \multirow{2}{*}{$\begin{array}{l}\text { Tarefas de } \\
\text { Visualização }\end{array}$} & \multicolumn{2}{|c|}{ Reflexão } & \multicolumn{2}{|c|}{ Ruminação } & \multicolumn{2}{|c|}{ Mediação Icônica } \\
\hline & $r$ & $p$ & $r$ & $p$ & $r$ & $p$ \\
\hline 01. Gerar $\left(\mathrm{S}^{\dagger}\right)$ & 0,004 & 0,955 & $-0,032$ & 0,613 & $0,177 * *$ & 0,004 \\
\hline 02. Inspecionar (S) & 0,039 & 0,553 & $-0,092$ & 0,158 & 0,084 & 0,197 \\
\hline 03. Encontrar (S) & $-0,020$ & 0,748 & 0,094 & 0,133 & $0,160 *$ & 0,010 \\
\hline 04. Zoom (S) & 0,067 & 0,282 & $\mathbf{0 , 1 2 3} *$ & 0,049 & $0,156^{*}$ & 0,012 \\
\hline 05. Rotar (S) & 0,005 & 0,941 & 0,028 & 0,652 & $0,196^{* *}$ & 0,002 \\
\hline 06. Transformar (S) & $-0,064$ & 0,309 & $-0,021$ & 0,740 & $0,181^{* *}$ & 0,004 \\
\hline 07. Controle Cinético (S) & 0,044 & 0,479 & 0,099 & 0,116 & $0,170^{* *}$ & 0,006 \\
\hline 08. Panoramizar (S) & 0,059 & 0,348 & 0,106 & 0,092 & $0,191 * *$ & 0,002 \\
\hline 09. Vividez (S) & 0,104 & 0,096 & $-0,043$ & 0,493 & $0,171 * *$ & 0,006 \\
\hline 10. Gerar $\left(\mathrm{NS}^{\ddagger}\right)$ & $-0,021$ & 0,737 & 0,039 & 0,533 & $0,176 * *$ & 0,005 \\
\hline 11. Inspecionar (NS) & $-0,038$ & 0,560 & $-0,076$ & 0,246 & 0,049 & 0,458 \\
\hline 12. Encontrar (NS) & $-0,024$ & 0,702 & 0,121 & 0,053 & 0,074 & 0,237 \\
\hline 13. Zoom (NS) & 0,065 & 0,297 & $0,170^{* *}$ & 0,006 & 0,090 & 0,149 \\
\hline 14. Rotar (NS) & 0,056 & 0,369 & 0,078 & 0,214 & $0,144 *$ & 0,021 \\
\hline 15. Transformar (NS) & 0,072 & 0,253 & $-0,009$ & 0,882 & 0,094 & 0,133 \\
\hline 16. Controle Cinético (NS) & 0,037 & 0,554 & $-0,046$ & 0,467 & $0,201 * *$ & 0,001 \\
\hline 17. Panoramizar (NS) & 0,041 & 0,509 & $-0,024$ & 0,701 & 0,090 & 0,151 \\
\hline 18. Vividez (NS) & $-0,028$ & 0,656 & 0,110 & 0,080 & 0,030 & 0,631 \\
\hline THV Série Self & 0,035 & 0,577 & 0,054 & 0,386 & $\mathbf{0 , 2 3 7 * *}$ & 0,001 \\
\hline THV Série Não-Self & 0,025 & 0,685 & 0,050 & 0,424 & $0,142 *$ & 0,023 \\
\hline
\end{tabular}

Notas. ${ }^{\dagger}$ S: Self; ${ }^{\star}$ NS: Não-Self; ${ }^{*} p \leq 0,05 ; * * p \leq 0,01$. 
Nascimento, A. M. \& Roazzi, A. (2013). Autoconsciência, Imagens Mentais e Mediação Cognitiva.

Tendo-se verificado a adequação psicométrica do instrumento de mensuração das habilidades cognitivas de manipulação de imagens mentais, encaminhou-se o teste da hipótese das relações entre autoconsciência e tais habilidades imagéticas através do coeficiente de correlação de Pearson sobre as intercorrelações entre as medidas de visualização e os fatores da Escala de Autoconsciência Situacional, cujos resultados estão relatados na Tabela 3 .

O exame dos $r$ de Pearson pôs em evidência 13 correlações estatisticamente significantes (em negrito na Tabela 3) na interface das medidas de visualização e dos escores dos fatores de Autoconsciência Situacional, sendo 04 delas significantes a $p<0,05$ e 09 das mesmas significantes a $p<0,01$, o que dá indicação da força da relação entre as variáveis consideradas. Os escores de Pearson variaram de $r=0,201, p<0,01$ no item 16 (Controle Cinético Não-Self, Mediação Icônica) a $r=0,123, p<0,05$ no item 04 (Zoom Self, Ruminação).

Nota-se de inicio a ausência de correlações significantes entre as operações de visualização de ambas as séries (Self e Não-Self) e o fator Reflexão da Escala EAS, o que deve ser compreendido teoricamente pela ênfase do conteúdo deste fator na valência do autoconteúdo trazido à consciência e no modo de agenciamento dos sistemas atencionais sobre o referido conteúdo (flexível ou estereotipado), e não sobre o caminho cognitivo que suporta as citadas operações de instanciação do autofoco (mediação cognitiva por imagens mentais ou autofala), lembrando-se que autoconsciência tem múltiplas fontes, inclusive não-cognitivas (externas ao self) e ambientais (ver Morin, 2004).

Um achado digno de nota no que tange ao fator Ruminação foi encontrado no exame dos escores de Pearson, a saber, as correlações estatisticamente significantes de $r=$ 0,123, $p<0,05$ no item 04 (Zoom Self, Ruminação) e $r=$ 0,170, $p<0,01$ no item 13 (Zoom Não-Self, Ruminação), correlações moderadas que analisadas em contraste com um corpo crescente de literatura que interfacia autoconsciência e psicopatologia, nos alerta para a existência de formas de autoconsciência negativamente motivadas, estereotípicas, com parco controle voluntário do sujeito e de natureza imagética, ligadas a acontecimentos, conflitos e experiências traumáticas (ver Morin, 2002; Trapnell \& Campbell, 1999; Zanon \& Teixeira, 2006).

A análise da matriz de correlações referente ao fator Mediação Icônica oferece um dos resultados mais expressivos em apoio à hipótese da mediação cognitiva de autoconsciência através das imagens mentais. Dos coeficientes de correlação encontrados, 11 de 18 são estatisticamente significantes, evidenciando que as mesmas não podem acontecer devido a erro amostral, sendo 03 delas significantes a $p<0,05$ e 08 das mesmas significantes a $p<0,01$. Os escores de Pearson variaram de $r=0,201, p<0,01$ no item 16 (Controle Cinético Não-Self, Mediação Icônica) a $r=0,144, p<0,05$ no item 14 (Rotar Não-Self, Mediação Icônica), o que satisfaz a Hipótese 4 do estudo.
Nota-se a maior incidência de correlações estatisticamente significantes na Série Self do THV, estando a série quase integralmente relacionada com o fator Mediação Icônica da escala EAS, conforme previsto na quinta Hipótese (H5). Intra-escala os coeficientes de mais força apresentados foram os de $r=0,196, p<0,01$ no item 05 (Rotar Self, Mediação Icônica), imediatamente seguido pelo $r=0,191$, $p<0,01$ no item 08 (Panoramizar Self, Mediação Icônica). Se de modo global os achados suportam a inferência de que altos níveis de habilidade em operar sobre imagens mentais e material icônico relacionado ao self se correlacionam de modo positivo e forte com escores de mediação de autoconsciência por imagens mentais (mediação icônica), de modo mais particularizado, essa visualização do self por si mesmo se dá preferentemente usando-se as operações 'rotar', a qual propicia escrutínio do objeto-self a partir de múltiplos ângulos e coordenadas espaciais, gerando uma rica expressão de modos de autovisualização do self; por outro lado, a operação 'panoramizar' permite uma percepção de modo globalizante e que contempla as formas complexas de engate e relacionamento self-ambiente que poderão a partir desse caminho cognitivo ser apreciadas com mais requinte descritivo e de modo mais ajuizado aquilatadas em sua significação, suportadas nessa dinâmica de mediação pelas demais operações de visualização também achadas estatisticamente significantes pelo coeficiente de correlação de Pearson.

Uma vez que desde James (1890/1968) pelo menos se tem investigado a estrutura de organização do self do animal humano em suas dimensões concretas, não só da base física - o corpo próprio - mas também das coisas, objetos inanimados com os quais o agente humano se vincula afetivamente e o entorno (Surroundings) imediato à fronteira representada pela pele - o ambiente físico à extensão de atuação do self (ver Morin, 1998, 2004; Wiley, 1996), faz sentido a presença de achados estatisticamente significantes com a mediação cognitiva de autoconsciência representadas pelas correlações $r=0,201, p<0,01$ no item 16 (Controle Cinético Não-Self, Mediação Icônica) - mais alta correlação individual encontrada neste exame; $r=$ 0,176, $p<0,01$ no item 10 (Gerar Não-Self); e $r=0,144$, $p<0,05$ no item 14 (Rotar Não-Self, Mediação Icônica). Esse resultado último indicia a importância dos elementos periféricos (mais concretos) na composição da estrutura do self humano, estando a correlação mais alta das séries em análise indicando a importância da criação e operação sobre a dinâmica de movimento (cinética) dos objetos não-self, sendo esta correlata a também estatisticamente significante relação encontrada entre mediação icônica e a operação 'controle cinético self', sendo uma operação complementar e necessária uma a outra - replicar e construir quadros ricos e cheios de movimento em que objetos self e não-self se articulam de modos complexos e transformativos na ambiência imaginativa (registro cognitivo).

Observando-se as relações dos mesmos fatores de autofoco com as operações visualizadoras tomadas em bloco pelas séries individuais do THV, a estatística $r$ de 
Pearson encontrou correlações significantes envolvendo a Série Self e Não-Self apenas com o fator Mediação Icônica ( $r=0,237$ e $r=0,142$, respectivamente), a primeira das intercorrelações com um escore mais alto que os demais, quando observados pelos itens isoladamente.

Em consideração à importância de análises de regressão para teste de hipóteses de mediação em psicologia (ver Kenny, 2011; MacKinnon, Fairchild, \& Fritz, 2007), no exame da validade de construto do THV e da função de mediação que as habilidades de visualização exercem na instanciação de autofoco, verificou-se o valor preditor das duas dimensões do THV na EAS através da computação de uma série de regressões passo-a-passo considerando como variáveis dependentes cada uma das dimensões de autoconsciência da escala EAS e como variáveis independentes as duas dimensões do THV.

Tabela 4

Análises de Regressão Passo-a-passo considerando como Variável Dependente a Dimensão Mediação Icônica da EAS e como Variáveis Independentes os Dois Fatores Self e Não Self do THV

\begin{tabular}{lcccccccc}
\hline Modelo & $R$ & $R^{2}$ & $R^{2}$ Corrigido & $R^{2}$ Change & FChange & gll & gl2 & $p$ \\
THV-Self & 0,238 & 0,057 & 0,053 & 0,057 & 15.35 & 1 & 255 & 0,001 \\
\hline
\end{tabular}

Os resultados apresentados na Tabela 4 apontam que somente o THV-Self desempenhou um papel preditor, mas apenas no fator Mediação Icônica, explicando 5,7\% da variância. Os outros dois fatores não apresentaram valores preditivos.

Consubstanciando o exame da mediação através das regressões supracitadas, efetuou-se uma Análise da Estrutura de Similaridade (SSA; Guttman, 1968; Young, 1987) com os fatores das escalas EAS e THV (Self e Não Self). O SSA é um tipo de escalonamento multidimensional não métrico onde as observações são representadas em um espaço de tipo euclidiano, organizado segundo o princípio da contigüidade, no qual a força das interrelações entre os itens é representada pelo inverso da distância entre os pontos, isto é, quão mais associadas duas variáveis estejam empiricamente, mais contíguas e próximas estarão na projeção multidimensional resultante. As hipóteses da pesquisa são perspectivadas em termos de regiões ou facetas, que a Teoria das Facetas prescreve serem justificadas logicamente em termos de apreciação sobre ordem (ou não ordem) dos elementos dessas estruturas espacializadas em subregiões do plano multidimensional (Guttman, 1968; ver Nascimento \& Roazzi, 2008; Roazzi, \& Dias, 2001).

Conforme verifica-se na estrutura da projeção SSA encontrada (ver Figura 1), o fator Ruminação encontra-se isolado no quadrante superior direito da projeção e distanciado dos demais fatores de autoconsciência, bem como dos de habilidades de visualização. No quadrante inferior direito e mais aproximados encontram-se Reflexão e Mediação Icônica, estando esta última, na interface com o quadrante inferior esquerdo, onde encontram-se aproximados conformando uma faceta coesa os dois fatores do THV (Self e Não Self). Há que se considerar a maior proximidade entre o fator THV-Self e o fator de Mediação Icônica da EAS, o que reforça a tese da mediação cognitiva de autoconsciência por imagens mentais, bem como a da validade de construto do instrumento que as mensura neste estudo - o THV, em especial, sua Série Self.

Estes achados corroboram a hipótese de estar a autoconsciência suportada não só por dinâmicas cognitivas discursivas (autofala) mas também associada a uma discursividade de tipo não-verbal, com uma fenomenologia construída em torno de visualizações do self, especialmente as relacionadas ao corpo e rosto próprios (imageria autoscópica), o que é esperado por teorias da cognição geral como a de Paivio (2007). Assim, autoconsciência situacional está relacionada a imagens mentais do self e de objetos self-relacionados, contudo, mais fortemente associada a visualizações focadas no self como as da Série Self.

\section{Discussão}

Apesar do robusto avanço da pesquisa sobre os processos autofocalizadores humanos nos últimos anos (ver Duval et al., 2001; Ferrari \& Sternberg, 1998; Govern \& Marsch, 2001; Morin, 1997, 2002, 2004; Nascimento, 2008; Silvia \& Duval, 2001; Silvia, Eichstaedt, \& Phillips, 2005; Silvia \& O’Brien, 2004), por motivos ainda a ser oportunamente esclarecidos por uma psicologia social do

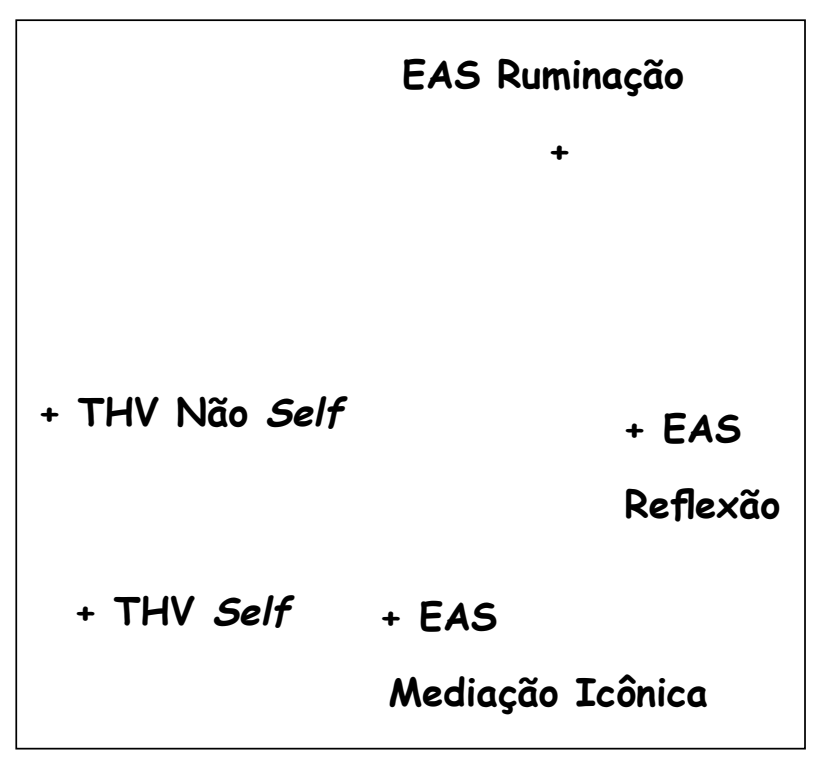

Figura 1. SSA das dimensões do THV e da EAS (Projeção 2d, Coeficiente de Alienação 0,001). 
Nascimento, A. M. \& Roazzi, A. (2013). Autoconsciência, Imagens Mentais e Mediação Cognitiva.

campo de estudos da autoconsciência no Brasil, em nosso país há uma notável assistematicidade no tratamento científico desse objeto, e os estudos publicados são raros e sem continuidade programática, sendo os trabalhos de autores como Gomes e Teixeira (1996), Nascimento (2008), Roazzi e Nascimento (2009), Silva e Nascimento (2007), Zanon e Teixeira (2006) exceções bem-vindas ao que parece ser um desinteresse à temática prevalecente. Nesse contexto de quase silêncio cientifico o presente trabalho visou inserir-se no debate internacional contemporâneo enfocando uma das mais urgentes questões sobre os processos de auto-inspeção humanos, a saber, a de por quais caminhos cognitivos os seres humanos prestam atenção a si mesmos, e se o uso de imagens mentais é instrumental nessa mediação.

Tomando-se de forma integrativa os achados relatados, indícios consistentes foram levantados para uma resposta favorável à hipótese de mediação cognitiva da autoconsciência situacional por imagens mentais conforme postulada no modelo de autoconsciência de Morin (2004). As correlações encontradas pelo coeficiente de correlação de Pearson evidenciam que os fatores reflexivo e ruminativo de autoconsciência encontram-se correlacionados de modo estatisticamente significante com o fator de mediação icônica de autoconsciência, isto é, quão mais autoconscientes, os individuos relatam usar imagens mentais para prestarem atenção a si mesmos e examinarem seus auto-aspectos codificados visualmente no autoconceito (ver Morin, 1998) usando as imagos do código dual da base cognitiva (Paivio, 2007) inscritos nas redes de self-schemata na memória.

Essa organização sistêmica da cognição em que autoconsciência, imagens mentais e o código dual da base do processamento cognitivo mediam intersistemicamente as dinâmicas estruturais e funcionais dos subsistemas cognitivos são bem evidenciados pelas correlações de Pearson encontradas no exame das intercorrelações entre fatores de autoconsciência e as habilidades de visualização, onde indivíduos mais autoconscientes tem escores mais altos nas ditas habilidades, evidência plausível para um desenvolvimento co-agenciado dos dois sistemas em foco. Assim, indivíduos mais hábeis em geração e processamento interno de imagens mentais, tem essa ferramenta mental mais à mão para fins introspectivos e auto-atentivos, sendo provavelmente o contrário também verdadeiro, em que os menos capazes na operacionalização do sub-sistema imagético devam exibir déficits específicos de autoconsciência, auto-experienciação e conseqüentemente, autoconceitos menos complexos e estruturados, e sub-desenvolvidos (ver Morin, 1995, 1998).

O fato de ambas as séries do THV (Self e Não-Self) estarem correlacionadas de modo positivo e estatisticamente significante com o fator de Mediação Icônica, reforça a tese do uso mediativo das imagens mentais na autoconsciência, posto que mais otimizados escores nas séries de visualização, e em especial na Série Self, estão relacionados sistematicamente a mais acentuados usos de imagens mentais para autofocalização. Reforços à hipótese advém do exame de correlações de itens individuais de ambos os sistemas onde rotinas computacionais do processamento imagético Zoom Selfe Zoom Não-Self encontram-se sistematicamente relacionados positivamente com o fator Ruminação de autoconsciência. É lícito inferir que a prevalência das correlações Zoom (Self e Não-Self) com Ruminação tem a ver com o caráter siderante de imagens mentais ocorrentes em quadros depressivos, ideação suicida e outras psicopatologias importantes (ver Botega, Barros, Oliveira, Dalgalarrondo, \& Marín-León, 2005; Chellappa \& Araújo, 2006; Freitas \& Botega, 2002) que retratam e rememoram ad infinitum possíveis experiências de desesperança, acontecimentos traumáticos e eventos/ situações de conflito ao self, as quais são aproximadas (zoom) - incluindo aí objetos não-self pertencentes ao contexto imediato dessas cenas reais ou fantasiadas, e visualizadas com requintes patológicos de detalhes, aumentando o sofrimento psíquico e a sobrecarga cognitiva associadas aos pensamentos ruminativos.

Outro achado dessas análises acrescenta elementos na defesa das imagens mentais na mediação de autoconsciência, especialmente às relacionadas a objetos não-self. Como encontrado, toda a Série Não-Self do THV está correlacionada de modo positivo e estatisticamente significante com o fator de Mediação Icônica de autoconsciência, o que se coloca como um índice empírico de proposições teóricas de autores como James (1890/1968), Morin (1998, 2004) e Neisser (1997) que sustentam a importância do significado da possibilidade de experienciação variegada e multidimensional (multi-angular) do ambiente físico com seus objetos para a própria emergência das noções de objeto e de interno-externo, essenciais a um self reflexivo e à autoconsciência. Assim, ontogeneticamente tendo se constituído uma consciência reflexiva na pluralidade e multiforme expressões do self-ambiente garantida pela locomoção, o sistema cognitivo pode replicar internamente mecanismos geradores e mantenedores de autoconsciência explorando de maneiras criativas a tridimensionalidade do self e de sua ambiência imediata recriando a cinética e a multi-angulação característica desses sistemas complexos, de que nos dão testemunho os escores de Pearson estatisticamente significantes que enlaçam consistentemente Mediação Icônica e Controle Cinético Não-Self e Rotar Não-Self, respectivamente (ver Tabela 3).

Como corolário do teste empírico da mediação cognitiva de autoconsciência por imagens mentais, os achados da análise de regressão consubstanciam os do exame das correlações, onde o THV-Self desempenhou um papel preditor sobre o fator mediativo da autoconsciência (mediação icônica), como também as duas séries do THV - e em especial o THV-Self, encontram-se posicionadas em grande proximidade a Mediação Icônica no quadrante inferior da projeção espacial construída pela análise SSA. O conjunto dos achados das análises de regressão e multidimensionais levanta indícios consistentes para uma mediação de autoconsciência por imagens mentais, além 
de sinalizarem evidências de validade de construto dos instrumentos em foco, a ser mais cuidadosamente investigada por via experimental posteriormente.

No presente, com base nos achados das análises realizadas, é mister uma maior cautela ao se emitir assertivas sobre os sistemas autofocalizadores humanos e seus mecanismos de mediação, levando-se em consideração a alta complexidade e intermitência de variáveis deste sistema, além do fato de as correlações encontradas no estudo serem em grande parte de fraca magnitude. Contudo, uma vez tais correlações terem sido geradas do exame de uma matriz de correlações dos dados de 258 participantes apenas (ver Método), é lícita a esperança de observar-se magnitudes mais expressivas dos escores do coeficiente de Pearson em amostra mais robusta. Lembramos adicionalmente que correlações fracas não são incomuns em fenômenos psicológicos multivariados, e que magnitudes de tal ordem são também encontradas em estudos internacionais de autoconsciência como o estudo clássico de validação da Self-Consciousness Scale de Fenigstein et al. (1975), onde a mais alta correlação encontrada é de 0,26 entre os fatores de autoconsciência privada e pública da Amostra 2. Situação similar foi encontrada no estudo de validação da versão desta escala em língua portuguesa do Brasil por Gomes e Teixeira (1996), onde os fatores de Autoconsciência Pública e Ansiedade Social apresentaram fraca correlação de 0,17 para a amostra feminina do estudo.

Um exame final das evidências levantadas no presente estudo convida-nos a considerar com seriedade a hipótese de que imagens mentais mediam autoconsciência situacional em humanos conforme postulado por Morin (2004), em suas formas reflexivas e ruminativas (Morin, 2002), devendo seus arranjos estruturais e funcionais a uma complexa história desenvolvimental em ambientes específicos (Paivio, 2007). Indícios emergentes nesta presente investigação que corroboram proposições recentes de multidimensionalidade da autoconsciência (Morin, 2002; Nascimento, 2008; Trapnell \& Campbell, 1999) colocam em imediato a necessidade de pesquisas adicionais cuidadosamente desenhadas, em especial os delineamentos experimentais e com uso de instrumentos de uso corrente que se coloquem como padrão áureo para análise da validade de construto das escalas em tela nesta investigação, e que esclareçam as relações entre esses dois subsistemas do autofoco humano, e de que modos imagens tanto externas quanto internas contribuem para suas mediações.

Uma vez que imagens mentais mediam autofoco de formas complexas nas interrelações com outros sistemas cognitivos, consideram-se primaciais no fomento do campo de estudos da autoconsciência em solo nacional, bem como mundial, um exame acurado do desenvolvimento desses sistemas de autofocalização no tempo desenvolvimental, e de como afetam e são afetados, pela história de constituição tanto da cognição em sentido geral em seu Sistema Dual Verbal-Imagético (Paivio, 2007) quanto na de sistemas cognitivos específicos como o autoconceito, raciocínio, formação de conceitos, linguagem e pensa- mento, na esteira das hipóteses de mediação sustentadas no presente trabalho.

\section{Referências}

Blumer, H. (1998). Symbolic interactionism: perspective and method. Berkeley, CA: University of California Press. (Original work published 1969)

Botega, N. J., Barros, M. B. A., Oliveira, H. B., Dalgalarrondo, P., \& Marín-León, L. (2005). Suicidal behavior in the community: Prevalence and factors associated with suicidal ideation. Revista Brasileira de Psiquiatria, 27(1), 45-53.

Buss, A. H. (2001). Psychological dimensions of the self. London: Sage.

Chellappa, S. L., \& Araújo, J. F. (2006). Relevância clínica de pesadelos em pacientes com transtorno depressivo. Revista de Psiquiatria Clínica, 33(4), 183-187.

Dancey, C. P., \& Reidy, J. (2006). Estatística sem matemática para psicologia (3. ed.) Porto Alegre, RS: Artmed.

Duval, T. S., Silvia, P., \& Lalwani, N. (2001). Self-awareness and causal attribution: A Dual Systems Theory. London: Kluwer Academic.

Duval, S., \& Wicklund, R. A. (1972). A theory of objective self awareness. New York: Academic Press.

Eysenck, M. W., \& Keane, M. T. (1994). Psicologia cognitiva: um manual introdutório. Porto Alegre, RS: Artes Médicas.

Fenigstein, A., Scheier, M. F., \& Buss, A. H. (1975). Public and private self-consciousness: Assessment and theory. Journal of Consulting and Clinical Psychology, 36, 1241-1250.

Ferrari, M., \& Sternberg, R. J. (1998). Self-Awareness: its nature and development. New York: The Guilford Press.

Finke, R. A. (1989). Principles of mental imagery. Cambridge, MA: The Massachusetts Institute of Technology Press.

Freitas, G. V. S., \& Botega, N. J. (2002). Gravidez na adolescência: Prevalência de depressão, ansiedade e ideação suicida. Revista da Associação Médica Brasileira, 48(3), 245-249.

Gibbons, F. X. (1990). Self-attention and behavior: A review and theoretical update. In M. P. Zanna (Ed.), Advances in experimental social psychology: Vol. 23 (pp. 249-303). New York: Academic Press.

Gomes, W. B., \& Teixeira, M. A. P. (1996). Escala de autoconsciência - revisada (EAC-R): Características psicométricas numa amostra de adolescentes brasileiros. Arquivos Brasileiros de Psicologia, 48(2), 78-92.

Govern, J. M., \& Marsch, L. A. (2001). Development and validation of the Situational Self-Awareness Scale. Consciousness and cognition, 10, 366-378.

Guttman, L. (1968). A general nonmetric technique for finding the smallest co-ordinate space for a configuration. Psychometrika, 33, 469-506.

Hair, J. F., Jr., Anderson, R. E., Tatham, R. L., \& Black, W. C. (2005). Análise multivariada de dados (5. ed., A. S. Sant'Anna $\&$ A. Chaves Neto, Trads.). Porto Alegre, RS: Bookman.

James, W. (1968). The Self. In C. Gordon \& K. J. Gergen (Eds.), The self in social interaction (pp. 41-49). New York: John Wiley \& Sons. (Original work published 1890)

Kenny, D. A. (2011). Mediation. Retrieved from http://davidakenny.net $/ \mathrm{cm} /$ mediate.htm

Kerlinger, F. N. (2003). Metodologia da pesquisa em Ciências Sociais: um tratamento conceitual (H. M. Rotundo, Trad.). São Paulo, SP: Editora Pedagógica e Universitária. (Original publicado em 1979) 
Kitamura, S. (1985). Similarities and differences between perception and mental imagery. Journal of Mental Imagery, 9(2), 83-92.

MacKinnon, D. P., Fairchild, A. J., \& Fritz, M. S. (2007). Mediation analysis. Annual Review of Psychology, 58, 593-614.

Mead, G. H. (1972). Mind, self and society. Chicago, IL: University of Chicago Press. (Original work published 1934)

Mohr, C., \& Blanke, O. (2005). The demystification of autoscopic phenomena: experimental propositions. Current Psychiatry Reports, 7, 189-195.

Morin, A. (1992). Une exploration théorique et empirique de l'existence d'une relation entre la conscience de soi et le dialogue intérieur (Thèse, École de Psychologie, Université Laval, Québec, Canada).

Morin, A. (1995). Preliminary data on a relation between self-talk and complexity of the self-concept. Psychological Reports, 76, 267-272.

Morin, A. (1997). History of exposure to self-focusing stimuli as a developmental antecedent of self-consciousness. Psychological Reports, 80, 1252-1254.

Morin, A. (1998). Imagery and self-awareness: A theoretical note. Theory and Review in Psychology. Retrieved July 06, 2005, from http://www.gemstate.net/susan/Imagry2.htm

Morin, A. (2002). Self-awareness review Part 1: Do you "selfreflect" or "self-ruminate"? Science \& Consciousness Review, 1. Retrieved July 06, 2005, from http://www2.mtroyal. ab.ca/ amorin/Rumination.pdf

Morin, A. (2004). A neurocognitive and socioecological model of Self-Awareness.Genetic, Social, and General Psychology Monographs, 130(3), 197-222.

Morin, A., \& Everett, J. (1991). Self-awareness and "introspective" private speech in 6-year-old children. Psychological Reports, 68, 1299-1306.

Morin, A., Everett, J., Turcotte, I., \& Tardif, G. (1993). Le dialogue intérieur comme médiateur cognitif de la conscience de soi privée: une mesure de l'activité de se parler à soi-même à propos de soi et une étude. La Revue Québécoise de Psychologie, 14(2), 3-19.

Nascimento, A. M. (2008). Autoconsciência situacional, imagens mentais, religiosidade e estados incomuns da consciência: um estudo sociocognitivo (Tese de doutorado, Pós-Graduação em Psicologia Cognitiva, Universidade Federal de Pernambuco, Recife, PE, Brasil).

Nascimento, A. M., \& Roazzi, A. (2008). Polifasia cognitiva e a estrutura icônica da representação social da morte. Psicologia: Reflexão e Crítica, 21(3), 499-508.

Neisser, U. (1997). The roots of Self-Knowledge: perceiving self, it, and thou. In J. G. Snodgrass \& R. L. Thompson (Eds.), The Self across Psychology: Self-Recognition, Self-Awareness, and the Self-Concept (pp. 19-33). New York: The New York Academy of Sciences.

Paivio, A. (1986). Mental representations: a dual coding approach. New York: Oxford University Press.

Paivio, A. (2006). Dual coding theory and education. Paper presented at the Conference on "Pathways to literacy achievement for high poverty children", Ann Arbor, MI. Retrieved July 20, 2008, from http://www.umich.edu/ rdytolrn/pathwaysconference/presentations/paivio.pdf

Paivio, A. (2007). Mind and its evolution: a dual coding theoretical approach. Mahwah, NJ: Lawrence Erlbaum.

Prieto, G. (2008). Las aptitudes espaciales. In A. Candeias, L. Almeida, A. Roazzi, \& R. Primi (Eds.), Inteligência: definição e medida na confluência de múltiplas concepções (pp. 81-126). São Paulo, SP: Casa do Psicólogo.
Pylyshyn, Z. W. (2002). Mental Imagery: in search of a theory. Behavioral and Brain Sciences, 25(2), 157-182.

Reis, E. (2001). Estatística Multivariada Aplicada (2. ed.). Lisboa, Portugal: Edições Silabo.

Roazzi, A., \& Dias, M. G. B. B. (2001). Teoria das facetas e avaliação na pesquisa social transcultural: explorações no estudo do juízo moral. In Conselho Regional de Psicologia - $13^{\mathrm{a}}$ Região PB/RN (Ed.), A diversidade da avaliação psicológica: Considerações teóricas e práticas (pp. 157-190). João Pessoa, PB: Idéia.

Roazzi, A., \& Nascimento, A. M. (2009). Neurônios espelho e seu impacto sobre a compreensão contemporânea dos fenômenos cognitivos In M. R. Souza \& F. C. S. Lemos (Eds.), Psicologia e Compromisso Social: Unidade na Diversidade (pp. 115-173). São Paulo, SP: Escuta.

Shepard, R. N., \& Cooper, L. A. (1986). Mental Images and Their Transformations. Cambridge, MA: The Massachusetts Institute of Technology Press.

Silva, R. M., Júnior, \& Nascimento, A. M. (2007). Autofala e a questão da mediação de Autoconsciência Pública. In Anais Eletrônicos do V Congresso Norte-Nordeste de Psicologia - CONPSI (pp. 1524-1525). Maceió, AL: Editora da Universidade Federal de Alagoas.

Silvia, P. J., \& Duval, T. S. (2001). Objective Self-Awareness Theory: Recent Progress and Enduring Problems. Personality and Social Psychology Review, 5(3), 230-241.

Silvia, P. J., Eichstaedt, J., \& Phillips, A. G. (2005). Are rumination and reflection types of self-focused attention? Personality and Individual Differences, 38, 871-881.

Silvia, P. J., \& O'Brien, M. E. (2004). Self-awareness and constructive functioning: revisiting "The human dilemma". Journal of Social and Clinical Psychology, 23(4), 475-489.

Trapnell, P. D., \& Campbell, J. D. (1999). Private self-consciousness and the Five-Factor Model of personality: distinguishing rumination from reflection. Journal of Personality and Social Psychology, 76(2), 284-304.

Wiley, N. (1996). O Self Semiótico. São Paulo, SP: Edições Loyola.

Young, F. W. (1987). Multidimensional scaling: history, theory and applications. Hillsdale, NJ: Erlbaum.

Zanon, C., \& Teixeira, M. A. P. (2006). Adaptação do Questionário de Ruminação e Reflexão (QRR) para estudantes universitários brasileiros. Interação em Psicologia, 10(1), 75-82. 


\section{Anexo \\ Teste de Habilidades de Visualização de Imagens Mentais - THV (Séries Self e Não-Self)}

\section{Bateria de Avaliação das Habilidades de Visualização}

Instrução: Os seres humanos em geral têm a capacidade de pensar usando imagens e criando cenas na mente, embora essa capacidade varie de pessoa a pessoa, havendo alguns que tem uma imaginação bem vívida e outros que afirmam que não conseguem ver com clareza imagens em seus pensamentos. As tarefas que seguem procuram avaliar a sua capacidade de lidar com imagens da imaginação. Leia cada uma das instruções a seguir com calma e procure executar em sua mente o que é pedido, uma tarefa por vez e sem pular a seqüência em que as tarefas são apresentadas, além de marcar com um $X$ após a leitura de cada instrução a afirmação que mais se aproxima da maneira como você vivenciou a tarefa, segundo a escala seguinte:

\begin{tabular}{|l|l|}
\hline $\mathbf{0}$ & Não visualizei imagens, apenas pensei no que me foi solicitado. \\
\hline $\mathbf{1}$ & Visualizei de forma muito vaga o que me foi solicitado. \\
\hline $\mathbf{2}$ & Visualizei de maneira pouco clara o que me foi solicitado. \\
\hline $\mathbf{3}$ & Visualizei com alguma clareza o que me foi solicitado. \\
\hline $\mathbf{4}$ & Visualizei claramente o que me foi solicitado. \\
\hline
\end{tabular}

\section{Tarefas de Imaginação}

1. Imagine um grande círculo pintado num terreno plano e pavimentado, com quatro placas de mesma altura que a sua, em que se observam escritas em grandes letras vermelhas as palavras 'Norte', 'Leste', 'Sul' e 'Oeste', dispostas segundo as marcações típicas de um relógio, ou seja, a placa Norte no ponto zero do relógio, a placa Leste no ponto equivalente a 3 horas, a placa Sul no ponto equivalente a 6 horas e a placa Oeste no ponto equivalente a 9 horas, todas elas dispostas de frente para o centro do círculo, no qual você se encontra de pé, com o rosto voltado para a placa Sul, de maneira que você visualize claramente a sua face na figura imaginada.

2. Visualizando você na mesma posição da tarefa anterior, com a face voltada para a placa Sul, encontre e leia o conteúdo da placa que deverá estar à esquerda do braço direito de sua imagem.

3. Visualizando você ainda com a face voltada para a placa Sul, localize em que parte provável de suas roupas está sua carteira de cédulas com seus documentos pessoais.

4. Visualizando você ainda com a face voltada para a placa Sul, aproxime a imagem cada vez mais perto de você até que você observe com o máximo de detalhes o ponto de seu rosto acima do nariz e entre as duas sobrancelhas.

5. Afaste a imagem de modo que você possa visualizar-se de corpo inteiro como na posição inicial e ainda com a face voltada para a placa Sul. Agora, gire a sua imagem para deixá-la de cabeça para baixo e com a face voltada para a placa Norte, de modo que você possa observar-se de costas e de ponta-cabeça.

6. Gire sua imagem de modo que ela retorne à posição inicial, de pé e com a face voltada para a placa Sul, de modo que você possa observar-se de frente e na posição face-a-face. Imagine-se com o dobro de sua altura real e com seus cabelos embranquecidos e pele enrugada como você se imagina ficar quando envelhecer, e olhando para placa Sul que deverá estar situada abaixo do nível da cabeça de sua imagem.

7. Imagine-se na situação inicial, com sua altura e cor de cabelos e textura da pele reais, de pé, na mesma altura das placas e com a face voltada para a placa Sul, de modo que você possa observar-se de frente e na posição face-a-face. Visualize sua imagem em posição de braços cruzados e parada neste ponto central, sem movimento, como numa fotografia. Após visualizar-se de forma fixa, imagine que sua imagem começa a movimentar-se caminhando ao redor de todo o círculo e tocando com a ponta dos dedos na primeira letra dos nomes inscritos em cada uma das placas, a começar pela placa Sul, e seguindo pelas placas Oeste, Norte, Leste, Sul novamente e retornando à sua posição inicial no centro do círculo e com a face voltada para a placa Sul.

8. Partindo da visualização de sua imagem na situação inicial, de pé e com a face voltada para a placa Sul, observe a cena inteira com sua imagem, as quatro placas e o círculo do alto, de maneira 
que você ao olhar deste ponto com uma visão panorâmica da cena, visualize a parte de cima da cabeça de sua imagem.

9. Imagine agora o círculo com as quatro placas como na imagem inicial, mas desta vez sem a sua imagem e com a presença no centro do círculo de um automóvel de quatro portas e de cor preta posicionado no ponto central do círculo, com a parte da frente que inclui faróis dianteiros e pára-brisa voltada para a placa Sul.

10. Visualizando o carro na mesma posição da tarefa anterior, com a parte da frente que inclui faróis dianteiros e pára-brisa voltada para a placa Sul, encontre e leia o conteúdo da placa que deverá estar na mesma direção do vidro e dos faróis traseiros do veículo de sua imagem.

11. Imaginando ter esquecido as chaves principais de sua casa ou apartamento dentro do carro, localize e visualize as chaves na parte provável em que elas devam estar no interior do automóvel.

12. Aproxime a imagem do automóvel cada vez mais perto de você até que você observe com o máximo de detalhes o pneu dianteiro direito.

13. Afaste a imagem até a posição inicial, com o automóvel posicionado no ponto central do círculo, com a parte da frente que inclui faróis dianteiros e pára-brisa voltada para a placa Sul. Gire o automóvel de modo que ele fique com os pneus para cima e com sua parte da frente voltada na direção da placa Leste.
14. Gire sua imagem de modo que ela retorne à posição inicial, com o automóvel posicionado no ponto central do círculo, com a parte da frente que inclui faróis dianteiros e pára-brisa voltada para a placa Sul. Imagine que o automóvel tem a metade do tamanho, possuindo agora apenas duas portas e sendo da cor vermelha.

15. Imagine a situação inicial, em que um automóvel de quatro portas e de cor preta está posicionado no ponto central do círculo, com a parte da frente que inclui faróis dianteiros e pára-brisa voltada para a placa Sul. Visualize o automóvel parado, numa posição fixa, como numa fotografia. Após visualizá-lo de forma fixa, imagine que o automóvel acende os faróis dianteiros e começa a se movimentar com os faróis piscando, saindo da posição inicial e contornando cada placa ao longo do círculo, a começar pela placa Sul, seguindo depois pelas placas Leste, Norte, Oeste, Sul novamente e por fim, parando no centro do círculo e desligando os faróis dianteiros, com os mesmos posicionados na direção da placa Norte.

16. Partindo da visualização do automóvel na situação anterior, posicionado no ponto central do círculo, com a parte da frente que inclui faróis dianteiros e pára-brisa voltada para a placa Norte, observe a cena inteira com o automóvel, as quatro placas e o círculo de um ponto no alto, acima deles, de maneira que você ao olhar deste ponto com uma visão panorâmica da cena, visualize a parte de cima do automóvel.

\section{Bateria de Avaliação da Vividez}

Instrução: Os testes seguintes avaliam a qualidade das imagens que você vai produzir de acordo com uma instrução específica sobre o que imaginar. Ao visualizar cada uma das imagens em seu pensamento, preste atenção aos detalhes delas e se você as consegue visualizar de maneira vívida e clara, com riqueza de detalhes de formas e cores, ou se elas aparecem em seu pensamento de maneira vaga e pouco elaborada, além de marcar com um X após cada visualização a afirmação que mais se aproxima da maneira como você vivenciou a tarefa, segundo a escala seguinte:

\begin{tabular}{|l|l|}
\hline $\mathbf{0}$ & Não visualizei imagens, apenas pensei no que me foi solicitado. \\
\hline $\mathbf{1}$ & Visualizei de forma muito vaga e sem vividez e clareza alguma o que me foi solicitado. \\
\hline $\mathbf{2}$ & Visualizei de maneira pouco vívida e clara o que me foi solicitado. \\
\hline $\mathbf{3}$ & Visualizei com alguma vividez e clareza o que me foi solicitado. \\
\hline $\mathbf{4}$ & Visualizei com absolutas vividez e clareza o que me foi solicitado. \\
\hline
\end{tabular}

1. Imagine-se caminhando à beira-mar, num dia claro de verão, com os pés molhando-se nas ondas que chegam na praia e seus cabelos se movendo ao toque dos ventos e seu rosto expressando um profundo sentimento de bem-estar e alegria pelas sensações que estão sendo experimentadas.
2. Visualize em seu pensamento a imagem de um automóvel amarelo e com os faróis piscando, estacionado em uma rua deserta ao meio-dia de um dia muito claro. 